\title{
Activated carbons from agricultural byproducts (pine tree and coconut shell), coal, and carbon nanotubes as adsorbents for removal of sulfamethoxazole from spiked aqueous solutions: Kinetic and thermodynamic studies
}

\author{
Marina Caldeira Tonucci, Leandro Vinícius Alves Gurgel, Sérgio Francisco de Aquino* \\ Departamento de Química, Instituto de Ciências Exatas e Biológicas, Universidade Federal de Ouro Preto, Campus Universitário Morro do Cruzeiro, \\ 35400-000 Ouro Preto, MG, Brazil
}

\section{A R T I C L E I N F O}

\section{Article history:}

Received 12 January 2015

Received in revised form 28 April 2015

Accepted 7 May 2015

Available online 21 May 2015

\section{Keywords:}

Adsorption

Kinetics

Thermodynamics

Sulfamethoxazole

Powdered activated carbon

Carbon nanotubes

\begin{abstract}
A B S T R A C T
In this study, four different adsorbent materials: commercial powdered activated carbon (PAC) from pine tree (PAC-I) and coconut shell (PAC-III) agricultural crop wastes, coal (PAC-II), and carbon nanotubes (CNT) were tested and compared for the removal of sulfamethoxazole (SMX) from spiked aqueous solutions. The kinetic, extrathermodynamic, and thermodynamic parameters for the adsorption of SMX on PACs and CNT were also determined. The results indicate that PAC-I was the best adsorbent for SMX adsorption. SMX adsorption was only favorable with PAC-I and CNT, leading to Gibbs free energies in the range of -39 to $-44 \mathrm{~kJ} \mathrm{~mol}^{-1}$ and showing that the adsorption process was spontaneous in all temperature ranges $\left(15-45^{\circ} \mathrm{C}\right)$ tested. Langmuir model best described SMX adsorption on PAC-I and led to maximum adsorption capacity of $\sim 131 \mathrm{mg} \mathrm{g}^{-1}$ (at $25^{\circ} \mathrm{C}$ ), which was $\sim 4.6$ times higher than that observed for CNT. The mechanism of SMX adsorption on PAC-I and CNT was suggested with basis on thermodynamic and extrathermodynamic parameters. The kinetic studies showed the pseudo-second-order model best described SMX adsorption, yielding $k_{2}$ values of 0.0035 and $0.0016 \mathrm{~g} \mathrm{mg}^{-1} \mathrm{~min}^{-1}$ for PAC-I and CNT, respectively.
\end{abstract}

(C) 2015 Elsevier B.V. All rights reserved.

\section{Introduction}

Powdered activated carbon (PAC) has been used as an effective adsorbent to remove organic matter, various classes of dyes, heavy metals, and pharmaceuticals from contaminated water (Acero et al., 2012; Çalışkan and Göktürk, 2010; Carabineiro et al., 2012; Delgado et al., 2012; Ogata et al., 2012). The efficiency of AC for removal of various pollutants is related to its great surface area, high porosity, and versatility (Mezohegyi et al., 2012). According to Duman et al. (2009), the production of activated carbon (AC) for commercial purposes has much to do with accessing resources, renewable resources, and processing to rigid specifications to control specific industrial and other applications. In particular, the demand for novel, renewable, and more efficient materials with low-cost and great local availability as precursors for AC production has

\footnotetext{
* Corresponding author. Tel.: +55 313559 1744; fax: +55 3135591707

E-mail address: sergio@iceb.ufop.br (S.F.d. Aquino).
}

increased (Momčilović et al., 2011). Nowadays, coal and lignocellulosic biomass are two major sources for the production of commercial ACs (Alslaibi et al., 2013; Duman et al., 2009). The abundance and availability of agricultural byproducts make them excellent sources of raw materials for AC production (Li et al., 2009). Harvesting and processing of various agricultural crops result in considerable amounts of various agricultural byproducts. Such byproducts are almost inexpensive, and in some cases, their effective utilization is a desired outcome (Li et al., 2009). Some examples of agricultural byproducts that have been successfully used in the preparation of AC are coconut shells, wood chips, sawdust, corn cobs, coffee husks, among others (Alslaibi et al., 2013; Duman et al., 2009). Among these agricultural by-products, coconut and pine tree have been widely used as precursors for AC production (Bhatnagar et al., 2010; Momčilović et al., 2011). Furthermore, ACs from coconut and pine tree have been studied as bioadsorbents for the removal of numerous types of pollutants from water due to their great availability (Bhatnagar et al., 2010; Momčilović et al., 2011). From 1980 to the 2010, the total coconut production world- 
wide increased expressively from 35 to 50 million tons (Bhatnagar et al., 2010). Moreover, many pine tree plantations around the world are required by pulp and paper industry, which increases the availability of residues from pine tree processing for various applications (Momčilović et al., 2011).

Another promising adsorbent that has attracted great attention for the removal of many kinds of organic and inorganic pollutants is carbon nanotubes (CNT). CNTs have large specific surface area, excellent mechanical properties, high chemical and thermal stability, and magnetic properties, which may facilitate its separation from water after use (Rao et al., 2007; Terrones, 2004).

Pharmaceutical compounds have been frequently detected in raw and treated sewage as well as in surface and groundwater in different countries; this is possibly related to the increased use of such chemicals in households and agro industries (Onesios et al., 2009; Rodrigues et al., 2014). Despite being detected in relatively low concentrations, some studies have proved the ability of such chemicals to cause mutagenic and genotoxic effects in aquatic organisms even at low doses; and, in the case of antibiotics, there is also the risk of such pharmaceuticals having adverse effects on humans (Fent et al., 2006; Richard et al., 2014).

Antibiotics are used worldwide in great amounts, and their an annual consumption was estimated to be $1169-109908 \mathrm{~g} \mathrm{ha}^{-1}$ year $^{-1}$ (de la Cruz et al., 2014; Van Boeckel et al. 2014). In particular, the antibiotic sulfamethoxazole (SMX) is widely used for the control of human infections (urinary, respiratory, and gastrointestinal), and it is also known that part of the pharmaceutical ingested is excreted as primary or secondary metabolites. In the case of SMX it is estimated that from 10 to $30 \%$ of the ingested dose is excreted via urine in its original form (Masters et al., 2003). Indeed, SMX has been detected in concentrations that range from dozens to hundreds $\mu \mathrm{g} \mathrm{L}^{-1}$ in sewage samples and from 14.8 to $297 \mathrm{ng} \mathrm{L}^{-1}$ in surface waters (Melo et al., 2009; Richard et al., 2014). Research suggests that such antibiotics can induce bacterial resistance and is suspected to cause liver cancer (Richard et al., 2014 Yargeau et al., 2008).

The conventional clarification processes (coagulation, flocculation, sedimentation, and filtration) adopted in most water treatment plants (WTPs) are primarily designed to remove particulate matter (turbidity) and pathogens, generally having little effect on the removal of organic microcontaminants (Lima et al., 2014). Therefore, other treatment technologies, such as adsorption processes, need to be investigated to complement the removal of pharmaceuticals from water (Santos et al., 2010).

This study aimed to compare the performance of three commercial PACs (pine tree (PAC-I), coal (PAC-II), and coconut shell (PAC-III)) and CNT for removal of SMX from spiked aqueous solutions and determine the kinetic, extrathermodynamic, and thermodynamic parameters of the adsorption process. Although PACs and CNT are potential adsorbents to complement the removal of SMX during water treatment, there is little information on the removal mechanisms and adsorption parameters that would allow a rational design of an adsorption unit in a WTP.

\section{Material and methods}

\subsection{Adsorbate}

SMX was chosen for this adsorption study due to its frequent occurrence in surface waters (Lima et al., 2014). The SMX standard used was purchased from Sigma-Aldrich ${ }^{\circledR}$ and was $100 \%$ pure (cat. no. S7507). Some physical-chemical properties of such compound are presented in the Table 1.

\subsection{Adsorbents}

Three types of powdered activated carbons (PACs), from distinct raw materials, were studied: PAC-I (pinus tree), PAC-II (mineral carbon), and PAC-III (coconut shell). PACs I and II were purchased from Carbosolution ${ }^{\circledR}$ and PAC-III from Carbonmar ${ }^{\circledR}$ Ltda. According to Carbosolution ${ }^{\circledR}$ and Carbonmar ${ }^{\circledR}$, the PAC-I and II were activated by steam at $800^{\circ} \mathrm{C}$, and PAC-III was also activated by steam $(0.980665 \mathrm{MPa})$ at $1000^{\circ} \mathrm{C}$, respectively. In its turn, the multi-walled carbon nanotube (CNT) was purchased from Sigma-Aldrich ${ }^{\circledR}$ (cat. no. 773840). All adsorbent materials were utilized in the adsorption tests without any pre-treatment and under $0.015 \mathrm{~mm}$ of grain size. Supplementary Tables $1-4$ list the technical specifications of PACs I-III and CNT provided by respective manufacturers.

\subsection{Adsorbents characterization}

\subsubsection{Point of zero charge (PZC)}

The PZC of the adsorbents PACs I-III and CNT was determined by the mass titration method (Noh and Schwarz, 1990). $\mathrm{NaNO}_{3}$ $(0.01 \mathrm{~mol} / \mathrm{L})$ solutions of $\mathrm{pH} 3,6$, and 11 were prepared using $0.1 \mathrm{~mol} / \mathrm{LHNO}_{3}$ and/or $\mathrm{NaOH}$ solutions to adjust the initial $\mathrm{pH}$ of the solutions. Samples of $20.0 \mathrm{~mL}$ of solutions of $\mathrm{pH} 3.6$, and 11 were added to $125 \mathrm{~mL}$ Erlenmeyer flasks containing different amounts of the adsorbents (PACs I-III or CNT) to obtain suspensions of 0.05 , $0.1,0.5,1.0,3.0,7.0$, and $10.0 \%(\mathrm{w} / \mathrm{w})$. The flasks were mechanically stirred at $25^{\circ} \mathrm{C}$ for $24 \mathrm{~h}$ at $200 \mathrm{rpm}$ in a shaker incubator (SoLab model SL-221). Then, the equilibrium pH values were measured using a $\mathrm{pH}$ meter.

\subsubsection{Specific surface area and pore size}

The specific surface area and pore size distribution of PACs I-III and CNT was determined by Brunauer-Emmett-Teller (BET) and Barret-Joyner-Halenda $(\mathrm{BJH})$ methods, respectively, in a BET surface area and pore size analyzer (Quantachrome Instruments, model NOVA 1000). Amounts varying from 1.0 to $1.5 \mathrm{~g}$ depending on the adsorbent type were degassed at $150^{\circ} \mathrm{C}$ under vacuum until there was no pressure variation ( $2 \mathrm{~h}$ ). Adsorption/desorption isotherms were measured using $\mathrm{N}_{2}$ at $77 \mathrm{~K}$.

\subsubsection{Fourier transform infrared spectroscopy (FTIR)}

The functional groups present on the surface of PACs I-III, and CNT were characterized by FTIR spectroscopy (Shimadzu, model IRAffinity-1) equipped with deuterated L-alanine-doped triglycine sulfate (DLATGS) detector. The FTIR spectra were recorded from 4000 to $400 \mathrm{~cm}^{-1}$ at a resolution of $4 \mathrm{~cm}^{-1}$ using diffuse reflectance infrared Fourier transform spectroscopy (DRIFTS). Samples dried at $105^{\circ} \mathrm{C}$ for $24 \mathrm{~h}$ were mixed with spectroscopy grade $\mathrm{KBr}$ using the sample-to- $\mathrm{KBr}$ ratio of 7:93 (w/w).

\subsection{Adsorption tests}

\subsubsection{Adsorption isotherms}

The adsorption tests were carried out according to the procedures described by the ASTM Standards on Activated Carbon (ASTM D3860-98, 2000), which establishes a contact time of $2 \mathrm{~h}$ for trial tests. The adsorption tests were carried out at $\mathrm{pH} 7.0$ to simulate the water $\mathrm{pH}$ in a WTP and at four different temperatures $(15,25$, 35 , and $45^{\circ} \mathrm{C}$ ) for thermodynamic purposes.

Erlenmeyer flasks of $250 \mathrm{~mL}$ containing $1.0 \mathrm{mg} \mathrm{L}^{-1}$ of SMX were pre-thermostated in a shaker incubator (SoLab model SL-221) for $45 \mathrm{~min}$. After temperature stabilization each flask received a different amount of adsorbent $(0.4,1.0,2.0,3.0,4.0,7.0,10.0,13.0,17.0$ or $20.0 \mathrm{mg}$ ) before being kept under stirring (150 rpm) for $2 \mathrm{~h}$. After 
Table 1

Physical-chemical properties of sulfamethoxazole (SMX).

\begin{tabular}{|c|c|c|c|c|}
\hline Size $(\AA)^{\mathrm{a}}$ & Chemical structure as a function of $\mathrm{pH}^{\mathrm{b}}$ & $\mathrm{MW}(\mathrm{g} / \mathrm{mol})^{\mathrm{c}}$ & $\mathrm{p} K_{\mathrm{a}}{ }^{\mathrm{d}}$ & $\log K_{\mathrm{ow}}{ }^{\mathrm{e}}$ \\
\hline 12.26 & & 253.28 & $\begin{array}{l}\mathrm{p} K_{\mathrm{a} 1}=1.7 \\
\mathrm{p} K_{\mathrm{a} 2}=5.6\end{array}$ & 0.89 \\
\hline
\end{tabular}

a Software ACD/ChemSketch.

b Chen et al. (2011).

c MW: molecular weight (The PubChem Project, 2012).

d Ka: acidity constant (Chen et al., 2011).

e Kow: octanol-water partition coefficient.

this time, about $5 \mathrm{~mL}$ of sample was withdrawn from each Erlenmeyer flask and then filtered through $0.45 \mu \mathrm{m}$ cellulose acetate membrane to remove any residual adsorbent. The filtered sample was then analyzed in a spectrophotometer (Aaker, Sp-220) for its absorbance at $267 \mathrm{~nm}$, which is the wavelength where SMX exhibits the maximum UV-vis absorption. The analytical curve built for SMX revealed a good linearity $\left(R^{2}>0.99\right)$ in the range from 0.025 to $10 \mathrm{mg} \mathrm{L}^{-1}$.

The amount of SMX adsorbed in the equilibrium $\left(q_{\mathrm{e}}\right)$ was estimated according to Eq. (1).

$q_{\mathrm{e}}=\frac{\left(C_{\mathrm{o}}-C_{\mathrm{e}}\right) V}{w}$

where $C_{\mathrm{o}}$ is the initial adsorbate (SMX) concentration $\left(\mathrm{mg} \mathrm{L}^{-1}\right), C_{\mathrm{e}}$ is the equilibrium adsorbate concentration $\left(\mathrm{mg} \mathrm{L}^{-1}\right), V$ is the volume of test solution $(\mathrm{mL})$ and $w$ is the weight of adsorbent used in each flask (g).

The adsorption isotherms of SMX on CAPs I-III and CNT was modeled using the Langmuir, Freundlich, Sips, and Temkin models. The Langmuir model (Langmuir, 1918) assumes a uniform energy of adsorption on the surface without adsorbate-adsorbate interaction. The energy of adsorption is constant in all adsorption sites and the adsorption occurs in monolayer (Carabineiro et al., 2012). The Langmuir model is given by Eq. (2) as follows:

$q_{\mathrm{e}}=\frac{Q_{\max } b C_{\mathrm{e}}}{1+b C_{\mathrm{e}}}$

where $q_{\mathrm{e}}\left(\mathrm{mgg}^{-1}\right)$ is the equilibrium adsorption capacity, $C_{\mathrm{e}}$ $\left(\mathrm{mg} \mathrm{L}^{-1}\right)$ is the concentration of SMX at equilibrium, $Q_{\max }\left(\mathrm{mg} \mathrm{g}^{-1}\right)$ is the maximum adsorption capacity of SMX per unit weight of adsorbent, and $b\left(\mathrm{~L} \mathrm{mg}^{-1}\right)$ is the Langmuir constant related to the energy of adsorption.

The separation factor, $R_{\mathrm{L}}$, is used to evaluate if the adsorption is favorable $\left(0<R_{\mathrm{L}}<1\right)$, unfavorable $\left(R_{\mathrm{L}}>1\right)$, linear $\left(R_{\mathrm{L}}=1\right)$ or irreversible $\left(R_{\mathrm{L}}=0\right)$. The $R_{\mathrm{L}}$ is calculated by Eq. (3) as follows:

$R_{\mathrm{L}}=\frac{1}{1+b C_{\mathrm{o}}}$

where $R_{\mathrm{L}}$ is the separation factor (dimensionless) (Acero et al., 2012).

The Freundlich model (Freundlich, 1906) considers heterogeneous adsorption and does not account for the saturation of the adsorption surface (Delgado et al., 2012). The Freundlich model is given by Eq. (4) as follows:

$q_{\mathrm{d}}=K_{\mathrm{f}} C_{\mathrm{e}}^{1 / n}$

where $K_{\mathrm{f}}\left(\mathrm{mg} \mathrm{g}^{-1}\left(\mathrm{~L} \mathrm{mg}^{-1}\right)^{1 / n}\right)$ is the Freundlich constant which indicates the relative adsorption capacity of the adsorbent and $n$ (dimensionless) is related to the adsorption intensity.
The Sips (Freundlich-Langmuir) model (Sips, 1948) identified the problem of the continuing, endless rise in the adsorption capacity with increasing the concentration in the Freundlich isotherm (Ferreira et al., 2015). Thus, he proposed an equation (Eq. (5)) similar to the Freundlich equation, but with a finite limit when the concentration is high enough. The Sips model is shown as follows:

$q_{\mathrm{e}}=Q_{\max } \frac{\left(b C_{\mathrm{e}}\right)^{1 / n}}{1+\left(b C_{e}\right)^{1 / n}}$

The Temkin model (Temkin and Pyzhev, 1940) assumes that the heat of adsorption of all molecules adsorbed on the surface decreases linearly with the coverage due to adsorbate-adsorbate interaction. The adsorption is also characterized by a uniform distribution of binding energies up to a maximum binding energy (Mezohegyi et al., 2012). The Temkin model is given by Eq. (6) as follows:

$q_{\mathrm{e}}=B \ln \left(A_{\mathrm{T}} C_{\mathrm{e}}\right)$

where $B\left(\mathrm{~J} \mathrm{~mol}^{-1}\right)$ is a constant related to heat of adsorption and $A_{\mathrm{T}}$ $\left(\mathrm{Lg}^{-1}\right)$ is the Temkin isotherm equilibrium binding constant.

$B=\frac{\mathrm{RT}}{b_{\mathrm{T}}}$

where $b_{\mathrm{T}}$ is the Temkin isotherm constant (dimensionless).

The non-linear regression analysis of the adsorption experimental data was performed using Microcal Origin $9.1^{\mathrm{TM}}$ set to use the iteration algorithm Levenberg-Marquardt, and the weight method used to minimize the chi-square $\left(\chi^{2}\right)$ was the statistical. The fitting of the isotherm models (Langmuir, Freundlich, Sips, and Temkin) to the experimental data was evaluated by both the determination coefficient $\left(R^{2}\right)$ and the normalized root mean square (NRMS), according to Eq. (8).

NMRS $=100 \sqrt{\frac{\sum_{i}^{N} \frac{\left(q_{\mathrm{e}, \exp }-q_{\mathrm{e}, \text { calc }}\right)}{q_{\mathrm{e}, \exp }}}{N}}$

where $N$ represents the number of experiments carried out.

Graphs of NMRS against $R^{2}$ (Supplementary Fig. 2) using the data presented in Table 2 for adsorption of SMX onto PACs I-III and CNT were built to investigate which isotherm model best described the adsorption phenomenon.

The adsorption energetic aspects were investigated by determining the thermodynamic parameters as changes in enthalpy $\left(\Delta H^{\circ}\right)$, entropy $\left(\Delta S^{\circ}\right)$, and Gibbs free energy $\left(\Delta G^{\circ}\right) . \Delta G^{\circ}$ was determined by Eq. (9) as follows:

$\Delta G^{o}=-R T \ln K_{\mathrm{a}}$ 
Table 2

Isotherm parameters obtained from non-linear regression analysis of SMX adsorption data using PACs I-III and CNT as adsorbents at $\mathrm{pH} 7.0,25^{\circ} \mathrm{C}$ and $2 \mathrm{~h}$ of contact.

\begin{tabular}{|c|c|c|c|c|}
\hline Adsorbent & PAC-I & PAC-II & PAC-III & CNT \\
\hline \multicolumn{5}{|l|}{ Langmuir isotherm } \\
\hline$Q_{\max }\left(\mathrm{mg} \mathrm{g}^{-1}\right)$ & 130.73 & 58.35 & - & 28.88 \\
\hline$b\left(\mathrm{Lmg}^{-1}\right)$ & 11.97 & 12.57 & - & 3.74 \\
\hline$R^{2}$ & 0.986 & 0.840 & - & 0.9733 \\
\hline NRMS (\%) & 2.893 & 5.344 & - & 1.758 \\
\hline \multicolumn{5}{|l|}{ Freundlich isotherm } \\
\hline$K_{\mathrm{f}}\left(\mathrm{mg} \mathrm{g}^{-1}\left(\mathrm{~L} \mathrm{mg}^{-1}\right)^{1 / n}\right.$ & 118.21 & 61.70 & 32.97 & 24.70 \\
\hline$n$ & 1.934 & 2.949 & 0.273 & 2.25 \\
\hline$R^{2}$ & 0.89945 & 0.95378 & 0.9631 & 0.9609 \\
\hline NRMS (\%) & 8.444 & 2.783 & 2.830 & 2.091 \\
\hline \multicolumn{5}{|l|}{ Temkin isotherm } \\
\hline$B\left(\mathrm{~J} \mathrm{~mol}^{-1}\right)$ & 31.13 & 11.33 & 82.60 & 6.79 \\
\hline$A_{\mathrm{T}}\left(\mathrm{Lg}^{-1}\right)$ & 38.98 & 159.63 & 1.48 & 31.04 \\
\hline$R^{2}$ & 0.9972 & 0.5924 & 0.8758 & 0.97186 \\
\hline NRMS (\%) & 2.466 & 4.254 & 4.328 & 1.754 \\
\hline \multicolumn{5}{|l|}{ Sips isotherm } \\
\hline$Q_{\max }\left(\mathrm{mg} \mathrm{g}^{-1}\right)$ & 128.45 & - & - & 31.97 \\
\hline$b\left(\mathrm{~L} \mathrm{mg}^{-1}\right)$ & 4.750 & - & - & 2.947 \\
\hline$n$ & 0.779 & - & - & 1.127 \\
\hline$R^{2}$ & 0.9910 & - & - & 0.9610 \\
\hline NRMS (\%) & 1.957 & - & - & 2.098 \\
\hline
\end{tabular}

(-) As the fitting was not adequate, no parameter value was presented.

where $T(K)$ is the absolute temperature, $R\left(8.314 \mathrm{~J} \mathrm{~K}^{-1} \mathrm{~mol}^{-1}\right)$ is the ideal gas constant, and $K_{\mathrm{a}}$ is the thermodynamic equilibrium constant. Since the adsorbate studied is weakly charged (stabilized by resonance), the activity coefficient $\left(\gamma_{\mathrm{e}}\right)$ is nearly 1.0 , making it possible to assume that $K_{\mathrm{a}}$ is equal to $b$, the Langmuir constant (Liu, 2009).

The relationship between the changes in Gibbs free energy, enthalpy, and entropy is given by Eq. (10), which combined with Eq. (9) yields the Eq. (11):

$\Delta G^{o}=\Delta H^{o}-T \Delta S^{o}$

$\ln K_{\mathrm{a}}=-\frac{\Delta H^{o}}{\mathrm{RT}}+\frac{\Delta S^{o}}{R}$

\subsubsection{Kinetic studies}

The kinetics of SMX adsorption was investigated only for PACI and CNT, which were the most favorable adsorbents tested. The kinetic tests were performed in batch mode with SMX solutions at the temperatures of $15,25,35$, and $45^{\circ} \mathrm{C}$. For this, Erlenmeyer flasks of $250 \mathrm{~mL}$ containing $100 \mathrm{~mL}$ of SMX solution $\left(1.0 \mathrm{mg} \mathrm{L}^{-1}\right)$ were pre-thermostated at the desired temperature for $45 \mathrm{~min}$ in a shaker incubator (SoLab SL-221). After this time each flask received $3.0 \mathrm{mg}$ of PAC-I or CNT and were kept under stirring $(150 \mathrm{rpm})$ for $120 \mathrm{~min}$. At preset time intervals $(5,10,15,30,45,60,75,90,105$, and $120 \mathrm{~min}$ ), $5 \mathrm{~mL}$ of sample was collected from each flask to determine the SMX concentration as previously described in Section 2.4.1.

Adsorption kinetic data of SMX on PAC-I and CNT were modeled using the pseudo-first-order, pseudo-second-order, and intraparticle diffusion kinetic models.

The pseudo-first-order model of Lagergren (Lagergren, 1898) assumes that the rate of adsorption of an adsorbate is directly proportional to the difference in the saturation concentration as given by Eq. (12) as follows:

$\frac{d q_{\mathrm{t}}}{d t}=k_{1}\left(q_{\mathrm{e}}-q_{\mathrm{t}}\right)$

where $q_{\mathrm{t}}$ and $q_{\mathrm{e}}\left(\mathrm{mg} \mathrm{g}^{-1}\right)$ are the adsorption capacities at a time $t$ and equilibrium, respectively, and $k_{1}\left(\mathrm{~min}^{-1}\right)$ is the pseudo-firstorder kinetic rate constant. Rearranging and integrating Eq. (12) using the boundary conditions of $q_{\mathrm{t}}=0$ at $t=0$ and $q_{\mathrm{t}}=q_{\mathrm{t}}$ at $t=t$, yields:

$q_{\mathrm{t}}=q_{\mathrm{e}}\left(1-\exp ^{-k_{1} t}\right)$

The pseudo-second-order model of Ho and Mckay (Ho and McKay, 1998) assumes that the rate of adsorption is dependent on the amount of solute adsorbed at the adsorbent surface at a time $t$ and equilibrium as given by Eq. (14) as follows:

$\frac{d q_{\mathrm{t}}}{d t}=k_{2}\left(q_{\mathrm{e}}-q_{\mathrm{t}}\right)^{2}$

where $k_{2}\left(\mathrm{~g} \mathrm{mg}^{-1} \mathrm{~min}^{-1}\right)$ is the pseudo-second-order kinetic rate constant. Rearranging and integrating Eq. (14) using the boundary conditions of $q_{\mathrm{t}}=0$ at $t=0$ and $q_{\mathrm{t}}=q_{\mathrm{t}}$ at $t=t$, yields:

$q_{\mathrm{t}}=\frac{k_{2} q_{\mathrm{e}}^{2} t}{1+k_{2} q_{\mathrm{e}} t}$

The intraparticle diffusion model of Weber and Morris (Weber and Morris, 1963) assumes that the intraparticle diffusion is the rate-determining step of the adsorption process. This model is defined by Eq. (16) as follows:

$q_{\mathrm{t}}=k_{\mathrm{id}} t^{1 / 2}+C$

where $k_{\text {id }}\left(\mathrm{mg} \mathrm{g}^{-1} \mathrm{~min}^{-1 / 2}\right)$ is the intraparticle diffusion rate constant and $C\left(\mathrm{mg} \mathrm{g}^{-1}\right)$ gives the thickness of the boundary layer.

The non-linear regression analysis of the kinetic data was performed using the same procedure described in Section 2.4.1.

The Eq. (17) and (18) and were used to calculate the Arrhenius activation energy and extrathermodynamic parameters as postulated by Arrhenius and Eyring, respectively:

$\ln k_{2}=\ln A-\frac{E_{\mathrm{a}}}{\mathrm{RT}}$

$\ln \left(\frac{k_{2}}{T}\right)=-\frac{\Delta H^{\ddagger}}{\mathrm{RT}}+\frac{\Delta S^{\ddagger}}{R}+\ln \left(\frac{k_{\mathrm{B}}}{h}\right)$

where $k_{2}\left(\mathrm{~g} \mathrm{mmol}^{-1} \mathrm{~min}^{-1}\right)$ is the pseudo-second-order rate constant, $E_{\mathrm{a}}\left(\mathrm{kJ} \mathrm{mol}^{-1}\right)$ is the Arrhenius activation energy, $A$ $\left(\mathrm{min}^{-1}\right)$ is the pre-exponential factor, $\Delta H^{\ddagger}\left(\mathrm{kJ} . \mathrm{mol}^{-1}\right)$ and $\Delta S^{\ddagger}$ $\left(\mathrm{J} \mathrm{K}^{-1} \mathrm{~mol}^{-1}\right)$ are the changes in activation enthalpy and entropy, $k_{\mathrm{B}}\left(1.3807 \times 10^{-23} \mathrm{JK}^{-1}\right)$ is the Boltzmann constant, and $h$ $\left(6.6261 \times 10^{-34} \mathrm{Js}\right)$ is the Planck constant.

\section{Results and discussion}

\subsection{Adsorbents characterization}

The PZC values determined for PACs I-III and CNT were 8.0, 10.5, 9.0, and 6.2, respectively. These PZC values indicate that all activated carbons tested (PACs I-III) are basic, and therefore, will have a positive net surface charge in the $\mathrm{pH}$ range (6.5-7.0) studied and in the WTPs. On the contrary, the PZC value for CNT indicates that it will have a negative net surface charge in the $\mathrm{pH}$ range tested.

The FTIR spectra of PACs I-III (Supplementary Fig. 1a-c) indicated the presence of a band at $3546 \mathrm{~cm}^{-1}$, corresponding to stretching vibration of $\mathrm{O}-\mathrm{H}$ groups in phenols. The bands at 3474 and $3412 \mathrm{~cm}^{-1}$ are related to stretching of $\mathrm{N}-\mathrm{H}$ groups in $\mathrm{N}$-heterocyclic as pyridines and pyrroles, and $\mathrm{N}-\mathrm{H}$ stretching in primary amides. The band at $3237 \mathrm{~cm}^{-1}$ is related to stretching of $\mathrm{C}-\mathrm{H}$ in alkynes, while the band at $2029 \mathrm{~cm}^{-1}$ corresponds to stretching of $C \equiv C$ in conjugated alkynes. The bands at 1638 and $1616 \mathrm{~cm}^{-1}$ are related to $\mathrm{C}=\mathrm{O}$ stretching and $\mathrm{N}-\mathrm{H}$ angular twist of primary amides, respectively. The broad band centered at $1098 \mathrm{~cm}^{-1}$ corresponds to 
stretching of $\mathrm{C}-\mathrm{O}$ in saturated aliphatic and aromatic alcohols, and the band at $615 \mathrm{~cm}^{-1}$ may also be related to out-of-plane bending of $\mathrm{C}-\mathrm{O}$ in alcohols (generally centered at $650 \mathrm{~cm}^{-1}$ ) and $\mathrm{C}-\mathrm{N}$ in amides (generally between 750 and $550 \mathrm{~cm}^{-1}$ ) (Larkin, 2011). These band assignments confirm that the main chemical groups present in the surface of PACs I-III are phenols, amides, pyridines, and pyrroles. These chemical groups can interact through hydrogen bonding with amine and sulfonamide groups, oxygen, and nitrogen atoms present in the chemical structure of SMX.

The FTIR spectra of CNT (Supplementary Fig. 1d) indicated the presence of a broad band centered at $3419 \mathrm{~cm}^{-1}$, corresponding to stretching of $\mathrm{O}-\mathrm{H}$ groups in alcohols and phenols, at $3235 \mathrm{~cm}^{-1}$ related to stretching of $\mathrm{C}-\mathrm{H}$ in vinyl and/or aromatic groups, at $1638 \mathrm{~cm}^{-1}$ related to conjugated $\mathrm{C}=\mathrm{O}$ with phenyl and/or $\mathrm{C}=\mathrm{C}$, at $1616 \mathrm{~cm}^{-1}$, corresponding to stretching of conjugated $-\mathrm{C}=\mathrm{C}-$ bonds, and at $619 \mathrm{~cm}^{-1}$ related to out-of-plane bending of $=\mathrm{C}-\mathrm{H}$ (Larkin, 2011). These bands indicate that the surface of CNTs has a certain amount of oxygen-containing functional groups. Similar band assignments for CNTs was made by Awadallah-F and Mostafa (2015).

As seen in Table 1, the speciation of SMX ( $\mathrm{p} K_{\mathrm{a}}$ values of 1.7 and 5.6)(Chen et al., 2011) in aqueous solution indicates that the SMX molecules are negatively charged in the $\mathrm{pH}$ range tested. Therefore, the SMX molecules are negatively charged and can be attracted by the PACs I-III, which have a positive net surface charge, favoring the adsorption phenomenon through electrostatic interaction.

On the other hand, the PZC determined for CNT was 6.2, indicating that this adsorbent is slightly acidic and will have a near zero net surface charge at the adsorption $\mathrm{pH}$. This result agrees somehow with that reported by Ji et al. (2009), who found PZC values for CNTs in the range from 5.2 to 8.4. Therefore, based on PZC value it is expected that CNT will not have an electrostatic affinity to SMX molecules.

A successful adsorption of any molecule depends not only on its approximation of the adsorbent surface, but also on its diffusion toward the inner pores where the proper interaction might take place. Analyzing the surface area and the porosity data, one might conclude that all PACs used in this study have significant volume of micropores (76.7, 88.5, and 92.8\% for PAC-I, II, and III, respectively), with pore diameter ranging from 11.07 to $18.22 \AA$, thereby classifying them as microporous materials. Ogata et al. (2012) employed different PACs to remove sulfa drugs from water samples and found pore sizes smaller (3.11$9.11 \AA$ ) than those reported in this study, although the PACs studied had greater surface areas $\left(>800 \mathrm{~m}^{2} \mathrm{~g}^{-1}\right.$ )(See Supplementary Table 5).

As it will be discussed later, there was a higher SMX adsorption on PAC-I when compared to the other adsorbent materials, and this might be related to the higher volume of meso- and macropores ( $23 \%)$ and the moderate surface area $\left(\sim 453 \mathrm{~m}^{2} \mathrm{~g}^{-1}\right)$ observed for this adsorbent. Although PAC-II had the highest surface area $\left(\sim 781 \mathrm{~m}^{2} \mathrm{~g}^{-1}\right)$ it had the lowest average pore diameter $(\sim 11.1 \AA)$ that is smaller than the SMX maximum length (see Table 1), which obviously creates some steric hindrance for adsorption of SMX. As far as PAC-III is concerned, although it exhibited the highest average pore size (18.22 $\AA$ ), it had the lowest surface area $\left(334 \mathrm{~m}^{2} \mathrm{~g}^{-1}\right)$ and the lowest total volume of pores $\left(\sim 0.23 \mathrm{~cm}^{3} \mathrm{~g}^{-1}\right)$.

Regarding the CNT characterization, the data gathered show this adsorbent had low specific surface area $\left(\sim 188 \mathrm{~m}^{2} \mathrm{~g}^{-1}\right)$. The volume of micropores found in the CNT corresponded to $23 \%$ of the total pore volume, indicating it has a greater amount of meso- and macropores. This would favor the adsorption of mid-size molecules such as SMX if it had a higher surface area. The average pore size $(\sim 14.5 \AA)$ is higher than the SMX maximum length, which facilitates bringing the drug into the adsorbent.

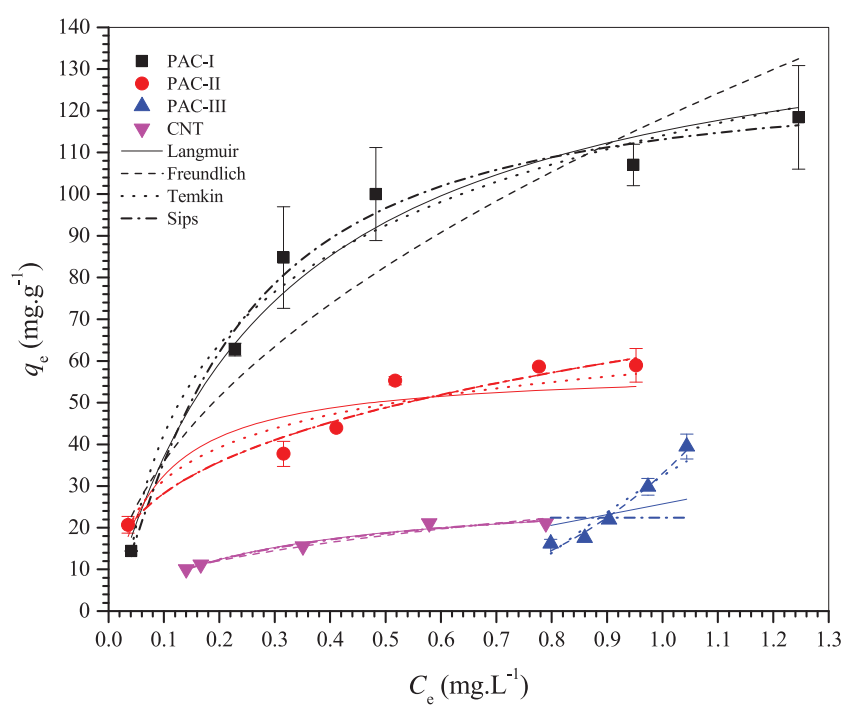

Fig. 1. Adsorption isotherms of SMX onto PACs I-III, and CNT for $2 \mathrm{~h}$ of contact at $\mathrm{pH} 7.0$ and $25^{\circ} \mathrm{C}$ (solid line: Langmuir model, dash line: Freundlich model, dot line: Temkin model, and dash dot line: Sips model).

\subsection{Adsorption studies}

\subsubsection{Adsorption isotherms}

The adsorption isotherms of SMX onto the four adsorbents tested (PACs I-III and CNT) at $25^{\circ} \mathrm{C}$ are presented in Fig. 1. Table 2 summarizes the parameters obtained from the non-linearized isotherm models (Langmuir, Freundlich, Sips, and Temkin) tested in this study.

According to the isotherm shape, it is possible to obtain valuable information on the adsorption process (Do, 1998). It is possible to conclude that SMX adsorption onto PAC-III is unfavorable due to its upward concavity, while for the other adsorbents the process is favorable. It is also obvious from Fig. 1 that PAC-I led to higher adsorption capacity and that CNT was the worst SMX adsorbent, probably due to its $\mathrm{PCZ}$ value and smaller surface area as previously discussed.

Table 2 presents the parameters for the isotherm models used to fit the experimental adsorption data of SMX onto PACs I-III and CNT. It can be seen that PAC-I had the best performance for SMX adsorption, exhibiting higher maximum adsorption capacity $\left(Q_{\max }\right)$ than PAC-II and CNT. In addition, the adsorption capacities reported in Table 2 compare well among the models tested, and are in accordance with the literature. For instance, Çalışkan and Göktürk (2010) studied SMX adsorption on PAC and found a maximum adsorption capacity of $185.19 \mathrm{mg} \mathrm{g}^{-1}$ which was closer to the value found in this study $\left(130.73 \mathrm{mg} \mathrm{g}^{-1}\right)$, employing similar adsorption conditions.

As can be seen in Table 2 and Supplementary Fig. 2, the Langmuir, Temkin, and Sips models best fitted SMX adsorption on PAC-I and CNT, whereas for PACs II and III the Freundlich model better described the adsorption phenomenon. The Langmuir model is associated with a homogeneous adsorbent surface and monolayer adsorption, which would relate to a more selective adsorption. Other authors (Çalışkan and Göktürk, 2010) who studied SMX adsorption on PAC also observed that the Langmuir model was the best to fit the experimental adsorption data. It is also seen in Table 2 that SMX adsorption on PACs II and III was best described by the Freundlich model, suggesting that such adsorption systems are more heterogeneous, and the adsorption might not be restricted to the formation of a monolayer. Since favorable adsorption conditions require $n$ values in the range from 1 to 10 , it is possible to say that only PAC-II had considerable affinity for SMX, thereby agreeing 

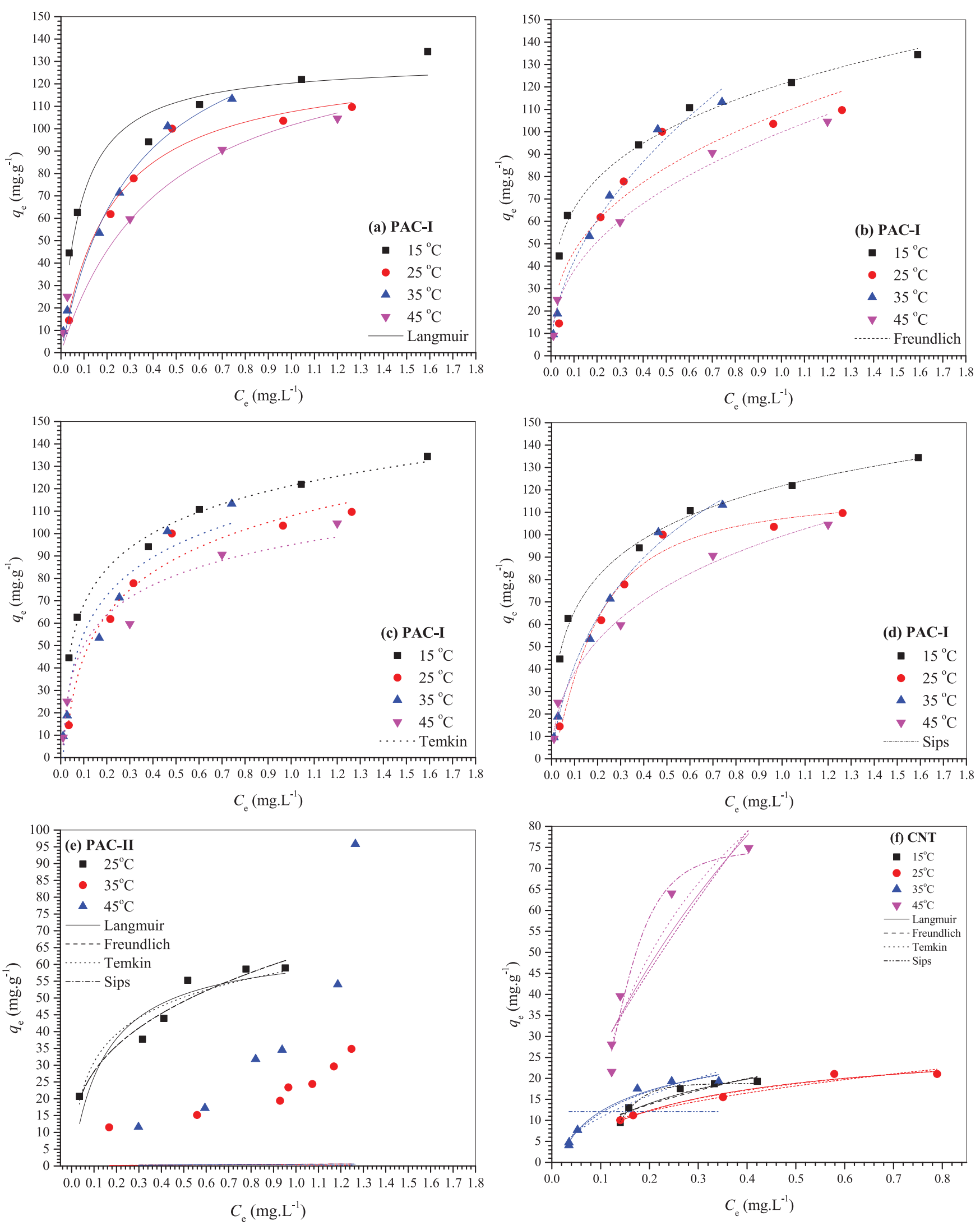

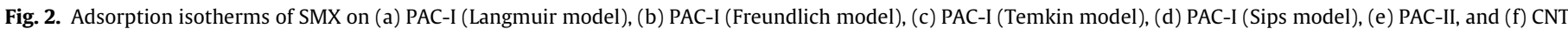
at $\mathrm{pH} 7.0$ for $2 \mathrm{~h}$ of contact at different temperatures. 
with the visual shape of the isotherm (Fig. 1). By analyzing the $K_{\mathrm{f}}$ parameter it is seen that $K_{\mathrm{f}, \mathrm{PAC}-\mathrm{II}}>K_{\mathrm{f} \text {,PAC-III }}$ confirming that PAC-III is not suitable for SMX adsorption.

Therefore, based on the adsorption data of SMX on PACs I-III and $\mathrm{CNT}$ at $25^{\circ} \mathrm{C}$, the effect of the temperature on SMX adsorption was evaluated only for PAC-I, II, and CNT as presented in Fig. 2a-f. Fig. 2e indicates that SMX adsorption on PAC-II becomes unfavorable with increasing the temperature.

The isotherm for SMX adsorption on PAC-I shows an initial upward inclination higher than that observed for PAC-II and CNT (Fig. 2a-d), thereby indicating a higher availability of adsorption sites on PAC-I. Moreover, SMX adsorption on CNT reached a plateau for the equilibrium adsorption capacity $\left(q_{\mathrm{e}}\right)$ (except for $45^{\circ} \mathrm{C}$ ) in lower adsorbate equilibrium concentrations when compared to PAC-I and II. This indicates that the SMX adsorption quickly reaches saturation, making it difficult for CNT to adsorb further SMX molecules.

According to the data presented in Table 3, for all temperatures tested the $R_{\mathrm{L}}$ values were between 0 and 1 , confirming a favorable adsorption of SMX on PAC-I and CNT. The values of Langmuir constant $(b)$ (for PAC-I and CNT) and Temkin binding constant $\left(A_{\mathrm{T}}\right)$ (for PAC-I) tended to decrease as the temperature increased, indicating there was a reduction in the affinity of the adsorption surface sites for SMX molecules. On the other hand, the maximum adsorption capacity, $Q_{\max }$, exhibited a slight increase as the temperature increased for adsorption of SMX on PAC-I, showing that SMX adsorption would be a viable process in the range of temperatures studied $\left(15-45^{\circ} \mathrm{C}\right)$. This is particularly important for the application of the commercial PAC-I adsorbent (from pine tree) in Brazil, where the average water temperature varies from $15^{\circ} \mathrm{C}$ (South) to $30^{\circ} \mathrm{C}$ (North). By comparing, the maximum adsorption capacities obtained for PAC-I and CNT, it is possible to see the superiority of the first for SMX adsorption. This is probably due to the higher PACI surface area, which would facilitate the access of SMX molecules throughout the adsorptive sites.

Summarizing the adsorption results, the PAC-I (activated carbon from pine tree) exhibited the best adsorption performance among all adsorbents tested. There are many pine tree plantations in different countries of northern and southern hemisphere, where pine trees are used for various applications including pulp and paper industry (Brown, 2000). Furthermore, pine tree processing produces a large amount of residues such as bark, needles, sawdust, and wood; the use of these residues is a desired outcome (Li et al., 2009). Therefore, the findings of this study are of great use since PAC-I is a low-cost adsorbent that can be prepared from an agricultural crop waste and its use in water treatment plants can be advantageous from both economic and performance viewpoints in various countries of the world.

3.2.1.1. Thermodynamic adsorption data. Table 4 shows that all $\Delta G^{\circ}$ values calculated for SMX adsorption on PAC-I and CNT were negative, indicating that the adsorption was spontaneous in the temperature range tested. The higher $\Delta G^{\circ}$ values (in module) observed for CNT, especially at lower temperatures, suggest that the adsorption process of SMX on CNT was more favorable than PAC-I. The $\Delta G^{\circ}$ values found in the study of Çalışkan and Göktürk (2010) were also negative and in the range from -2700 to $-1290 \mathrm{~J} \mathrm{~mol}^{-1}$, which would imply in a physical sorption, which notably involves lower energy content. Table 4 also shows that the temperature increase led to $\Delta G^{\circ}$ values more negative for both adsorbents PAC-I and CNT. This indicates that an increase in the temperature makes the adsorption process of SMX on PAC-I and CNT more spontaneous.

The negative $\Delta \mathrm{H}^{\circ}$ values obtained confirm that SMX adsorption is exothermic, which agrees with the earlier discussion on spontaneity and influence of temperature on the adsorption process. The differences between physisorption and chemisorption are that
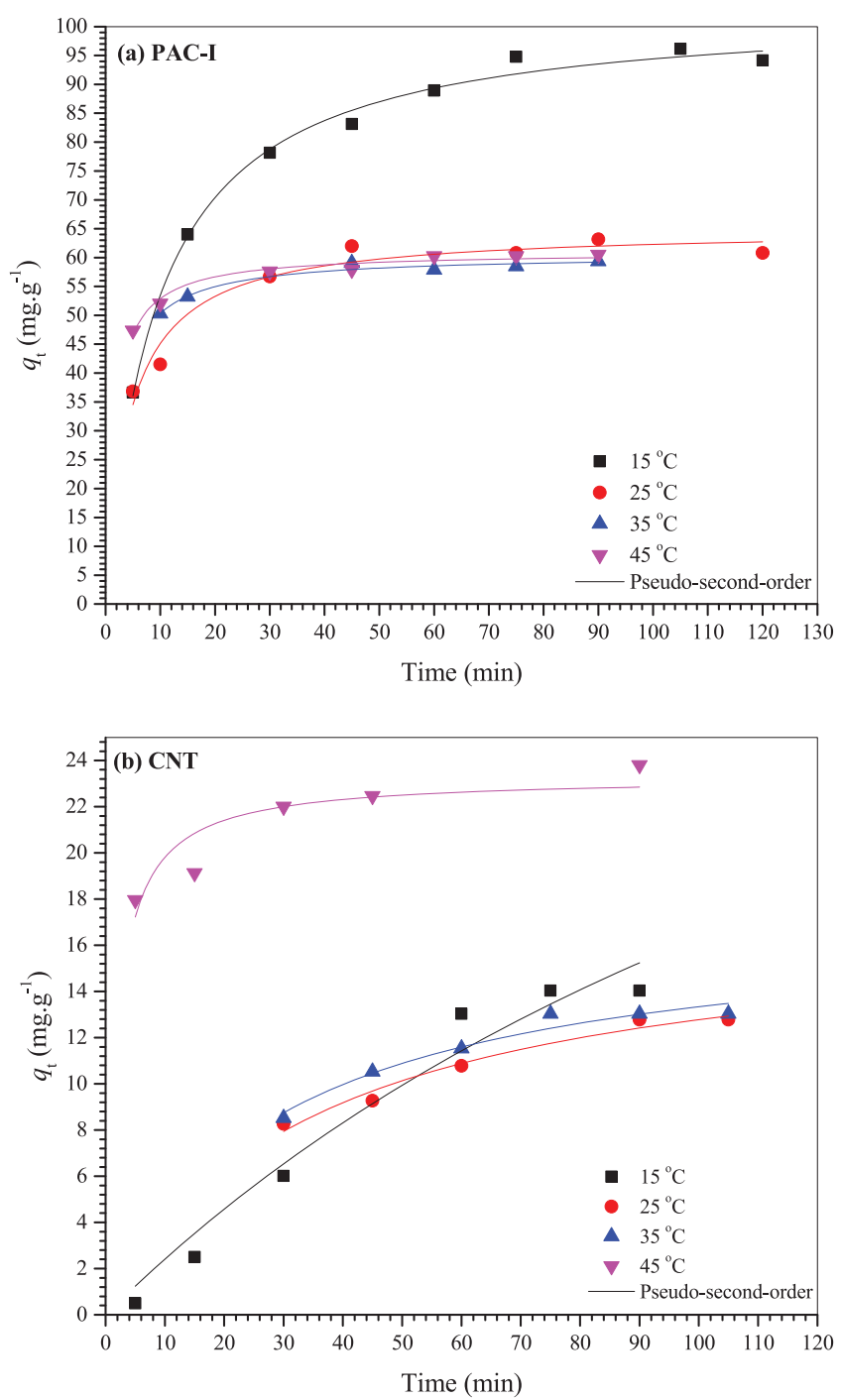

Fig. 3. Temporal changes in SMX adsorption capacity observed for (a) PAC-I and (b) CNT.

physisorption is characterized by weak bonds such as dipole-dipole interactions, dispersion forces, induction forces, and hydrogen bonding, with energies up to $40 \mathrm{~kJ} \mathrm{~mol}^{-1}$, whereas chemisorption is owing to strong bonding, with energies typically over to $80 \mathrm{~kJ} \mathrm{~mol}^{-1}$ (Buckton, 2000; Erbil, 2006; Worch, 2012). In addition, the $\Delta \mathrm{H}^{\circ}$ values for SMX adsorption on PAC-I and CNT were closer to the upper limit for physisorption. Thus, with basis on $\Delta \mathrm{H}^{\circ}$ values, the suggested mechanism for adsorption of SMX on PAC-I and CNT is physisorption. For PAC-I the main suggested interactions with SMX are electrostatic and hydrogen bonding, since PAC-I is positively charged and has heteroatoms on its surface and SMX is negatively charged in the $\mathrm{pH}$ range studied. While for CNT, the main suggested interactions with SMX are ion-dipole and $\pi-\pi$ interactions, since CNT is almost neutral and has less heteroatoms on its surface than PAC-I, and SMX is negatively charged in the $\mathrm{pH}$ range studied. As will be discussed in the Section 3.2.2.1, the Arrhenius activation energies for adsorption of SMX on PAC-I and CNT were higher than that expected for physisorption, which may suggest a mixed mechanism governing the adsorption process.

\subsubsection{Adsorption kinetics}

According to Ho (2006) the rate on which the adsorption happens is vital for dimensioning an adsorption unit in a WTP. Since the isotherms showed PAC-I and CNT were the most promising adsor- 
Table 3

Isotherm parameters for SMX adsorption on PAC-I and CNT at $\mathrm{pH} 7$ and $2 \mathrm{~h}$ of contact for different temperatures.

\begin{tabular}{|c|c|c|c|c|c|}
\hline Isotherm model & Temperature $(K)$ & 288.15 & 298.15 & 308.15 & 318.15 \\
\hline \multirow[t]{10}{*}{ Langmuir } & PAC-I & & & & \\
\hline & $Q_{\max }\left(\mathrm{mgg}^{-1}\right)$ & 130.40 & 130.73 & 162.56 & 146.48 \\
\hline & $b\left(\mathrm{~L} \mathrm{mg}^{-1}\right)$ & 11.97 & 4.64 & 3.21 & 2.26 \\
\hline & $R_{\mathrm{L}}$ & 0.00058 & 0.00156 & 0.00133 & 0.00098 \\
\hline & $R^{2}$ & 0.933 & 0.974 & 0.989 & 0.954 \\
\hline & CNT & & & & \\
\hline & $Q_{\max }\left(\mathrm{mg} \mathrm{g}^{-1}\right)$ & 33.58 & 29.08 & 30.58 & 80.21 \\
\hline & $b\left(\mathrm{~L} \mathrm{mg}^{-1}\right)$ & 3.59 & 3.69 & 6.20 & 1.28 \\
\hline & $R_{\mathrm{L}}$ & 0.312 & 0.232 & 0.269 & 0.339 \\
\hline & $R^{2}$ & 0.879 & 0.967 & 0.963 & 0.863 \\
\hline \multirow[t]{8}{*}{ Freundlich } & PAC-I & & & & \\
\hline & $K_{f}\left(\mathrm{mg} \mathrm{g}^{-1}\right)\left(\mathrm{L} \mathrm{mg}^{-1}\right)^{1 / \mathrm{n}}$ & 121.16 & 108.38 & 139.10 & 99.79 \\
\hline & $n$ & 3.75 & 2.72 & 1.93 & 2.39 \\
\hline & $R^{2}$ & 0.986 & 0.860 & 0.982 & 0.985 \\
\hline & CNT & & & & \\
\hline & $K_{\mathrm{f}}\left(\mathrm{mg} \mathrm{g}^{-1}\right)\left(\mathrm{L} \mathrm{mg}^{-1}\right)^{1 / n}$ & 32.42 & 24.61 & 39.99 & 161.73 \\
\hline & $n$ & 1.88 & 2.30 & 1.73 & 1.27 \\
\hline & $R^{2}$ & 0.834 & 0.948 & 0.908 & 0.841 \\
\hline \multirow[t]{8}{*}{ Temkin } & PAC-I & & & & \\
\hline & $B\left(\mathrm{~J} \mathrm{~mol}^{-1}\right)$ & 23.09 & 27.40 & 24.60 & 19.53 \\
\hline & $A_{\mathrm{T}}\left(\mathrm{Lg}^{-1}\right)$ & 191.82 & 51.25 & 94.67 & 129.25 \\
\hline & $R^{2}$ & 0.993 & 0.961 & 0.927 & 0.962 \\
\hline & CNT & & & & \\
\hline & $B\left(\mathrm{~J} \mathrm{~mol}^{-1}\right)$ & 8.56 & 6.83 & 7.12 & 42.46 \\
\hline & $A_{\mathrm{T}}\left(\mathrm{Lg}^{-1}\right)$ & 25.81 & 30.76 & 55.13 & 15.94 \\
\hline & $R^{2}$ & 0.887 & 0.964 & 0.974 & 0.917 \\
\hline Sips & PAC-I & & & & \\
\hline \multirow[t]{9}{*}{ (Langmuir-Freundlich) } & $Q_{\max }\left(\mathrm{mgg}^{-1}\right)$ & 241.40 & 118.68 & 215.00 & 270.29 \\
\hline & $b\left(\mathrm{Lmg}^{-1}\right)$ & 1.0434 & 5.397 & 1.639 & 0.368 \\
\hline & $n$ & 2.308 & 0.757 & 1.269 & 1.841 \\
\hline & $R^{2}$ & 0.991 & 0.978 & 0.991 & 0.985 \\
\hline & CNT & & & & \\
\hline & $Q_{\max }\left(\mathrm{mgg}^{-1}\right)$ & 18.87 & 29.85 & - & 74.94 \\
\hline & $b\left(\mathrm{~L} \mathrm{mg}^{-1}\right)$ & 7.23 & 3.48 & - & 6.95 \\
\hline & $N$ & 0.19 & 1.04 & - & 0.26 \\
\hline & $R^{2}$ & 0.971 & 0.951 & - & 0.954 \\
\hline
\end{tabular}

(-) Since the fitting was not adequate the parameter value was not presented.

bents for SMX removal, the kinetic studies were only carried out for these adsorbents. In this study, the kinetic models tested were pseudo-first and pseudo-second-order, and intraparticle diffusion model. However, since the pseudo-first-order did not correlate well with the experimental data points, the kinetic parameters determined from this model will not be presented.

Fig. 3 shows the temporal behavior of SMX adsorption capacity for PAC-I and CNT at different temperatures, whereas Table 5 shows the calculated kinetic parameters for the pseudo-secondorder model. It is seen in Fig. 3 that the equilibrium time for SMX adsorption is reached after $70 \mathrm{~min}$ for PAC-I and $80 \mathrm{~min}$ for CNT, which is lower than the time $(120 \mathrm{~min})$ chosen for the isotherm studies fixed according to ASTM protocols. Fig. 3 also shows that the pseudo-second-order model fitted well the experimental data and because of this, the calculated adsorption capacity $\left(q_{\mathrm{e}, \mathrm{calc}}\right)$ (Table 5 ) was very close to the observed experimental adsorption capacity $\left(q_{\mathrm{e}, \exp }\right)$ for both adsorbents. The values of equilibrium adsorption capacity observed in the kinetic studies were lower than the ones in
Table 5

Kinetic parameters calculated for the pseudo-second-order model for SMX adsorption on PAC-I and CNT at $25^{\circ} \mathrm{C}$ and $\mathrm{pH}$ 7.0.

\begin{tabular}{lllll}
\hline Adsorbent & Temperature $\left({ }^{\circ} \mathrm{C}\right)$ & \multicolumn{3}{l}{ Pseudo-second-order parameters } \\
\cline { 3 - 5 } & & $k_{2}\left(\mathrm{~g} \mathrm{mg}^{-1} \mathrm{~min}^{-1}\right)$ & $q_{\mathrm{e}, \mathrm{calc}}\left(\mathrm{mg} \mathrm{g}^{-1}\right)$ & $R^{2}$ \\
\hline PAC-I & 15 & 0.0011 & 103.21 & 0.992 \\
& 25 & 0.0035 & 64.85 & 0.948 \\
& 35 & 0.0082 & 60.54 & 0.964 \\
& 45 & 0.0108 & 61.00 & 0.971 \\
$\mathrm{CNT}$ & 15 & 0.00012 & 45.68 & 0.959 \\
& 25 & 0.0016 & 17.28 & 0.964 \\
& 35 & 0.0020 & 17.21 & 0.951 \\
& 45 & 0.0243 & 23.29 & 0.752 \\
\hline
\end{tabular}

the isotherm, which was because of the amount of adsorbent used in the kinetic experiments. When the $k_{2}$ values are compared it is possible to note that SMX adsorption on PAC-I is at least twice as faster than that observed for CNT, which correlates well with the

Table 4

Thermodynamic parameters for SMX adsorption on PAC-I and CNT at pH 7 and $2 \mathrm{~h}$ of contact for different temperatures.

\begin{tabular}{|c|c|c|c|c|c|c|}
\hline \multirow[b]{2}{*}{$T(K)$} & \multicolumn{3}{|l|}{ PAC-I } & \multicolumn{3}{|l|}{ CNT } \\
\hline & $\Delta H^{\circ}\left(\mathrm{kJ} \mathrm{mol}^{-1}\right)$ & $\Delta S^{\circ}\left(\mathrm{J} \mathrm{K}^{-1} \mathrm{~mol}^{-1}\right)$ & $\Delta G^{\circ}\left(\mathrm{kJ} \mathrm{mol}^{-1}\right)$ & $\Delta H^{\circ}\left(\mathrm{kJ} \mathrm{mol}^{-1}\right)$ & $\Delta S^{\circ}\left(\mathrm{J} \mathrm{K}^{-1} \mathrm{~mol}^{-1}\right)$ & $\Delta G^{\circ}\left(\mathrm{kJ} \mathrm{mol}^{-1}\right)$ \\
\hline 288.15 & & 7.179 & -38.80 & & & -43.59 \\
\hline 298.15 & & & & & & -43.75 \\
\hline & -36.73 & & -38.87 & -38.96 & 16.073 & \\
\hline 308.15 & & & -38.94 & & & -43.91 \\
\hline 318.15 & & & -39.01 & & & -44.07 \\
\hline
\end{tabular}


Table 6

Intraparticle diffusion model parameters for the SMX adsorption on PAC-I and CNT at $25^{\circ} \mathrm{C}$ and $\mathrm{pH} 7.0$.

\begin{tabular}{llllll}
\hline Parameters & PAC-I & & & \multicolumn{2}{l}{ CNT } \\
\cline { 2 - 3 } \cline { 5 - 6 } & 1st step & 2nd step & & 1st step & 2nd step \\
\hline$k_{\text {id }}\left(\mathrm{mg} \mathrm{g}^{-1} \mathrm{~min}^{-1 / 2}\right)$ & 5.81 & 0.05 & & 0.52 & - \\
$C\left(\mathrm{mg} \mathrm{g}^{-1}\right)$ & 23.71 & 60.18 & & 5.73 & - \\
$R^{2}$ & 0.995 & 0.564 & & 0.931 & - \\
\hline
\end{tabular}

data from the isotherm studies and might be related to the lower CNT specific area.

Considering the data presented in Table 5 it is possible to estimate that $100 \mathrm{~kg}$ of commercial PAC-I would be enough to treat (assuming $100 \%$ of removal) $17,700 \mathrm{~m}^{3} \mathrm{~d}^{-1}$ of water containing $1 \mu \mathrm{g} \mathrm{L}^{-1}$ of SMX needing only $5 \mathrm{~min}$ of contact. In a real case scenario, it would probably take more time and more mass of PAC-I to treat the same amount of water due to the competition with other water pollutants by PAC-I adsorption sites.

According to Gusmao et al. (2012) the adsorption follows the intraparticle diffusion mechanism when a plot of $q_{\mathrm{t}}$ versus $t^{1 / 2}$ yields a straight line and this straight line crosses the origin $(C=0)$, i.e., the intercept is equal to zero. There are many studies showing that such a plot may exhibit multilinearity (Nunes et al., 2011), which would characterize multi stages of the adsorption process, such as external mass transfer (from bulk solution to the adsorption surface) followed by the inner diffusion of the adsorbate into the macro-, meso-, and micropores.

In this study, the intraparticle diffusion model was tested to fit SMX adsorption data on both adsorbents, as shown in Fig. 4. It is seen that the straight lines did not cross the graph origin $(C \neq 0)$ indicating that the intraparticle diffusion is not the sole step that limits SMX adsorption on PAC-I and CNT. It is also seen that for PAC-I adsorbent the adsorption had at least two stages. The first stage was quicker and probably related to SMX mass transfer to the external adsorbent surface, while the second stage reflects a saturation condition and is dependent on SMX mass transfer to the inner pores. Whereas for CNT only the first stage was observed.

Based on the $k_{\text {id }}$ values presented in the Table 6 , it is possible to infer that, for PAC-I, the first step of adsorption (SMX mass transfer to the external adsorbent surface) is more relevant than the second one. The same was observed for CNT due to the lack of diffusion of intraparticle. This agrees with the fact that SMX adsorption on PAC-I was faster than on CNT.

3.2.2.1. Activation energy and extrathermodynamic parameters. The Arrhenius and extrathermodynamic parameters for the adsorption of SMX on PAC-I and CNT were calculated from the $k_{2}$ values (Table 5) and are presented in Table 7 . According to Anirudhan and Radhakrishnan (2008), the magnitude of activation energy may give an idea about the type of adsorption, i.e., physiand/or chemisorption. Values of activation energy $\left(E_{\mathrm{a}}\right)$ lower than $40 \mathrm{~kJ} \mathrm{~mol}^{-1}$ indicate physisorption and higher than $40 \mathrm{~kJ} \mathrm{~mol}^{-1}$ chemisorption. The Arrhenius activation energy $\left(E_{\mathrm{a}}\right)$ calculated for
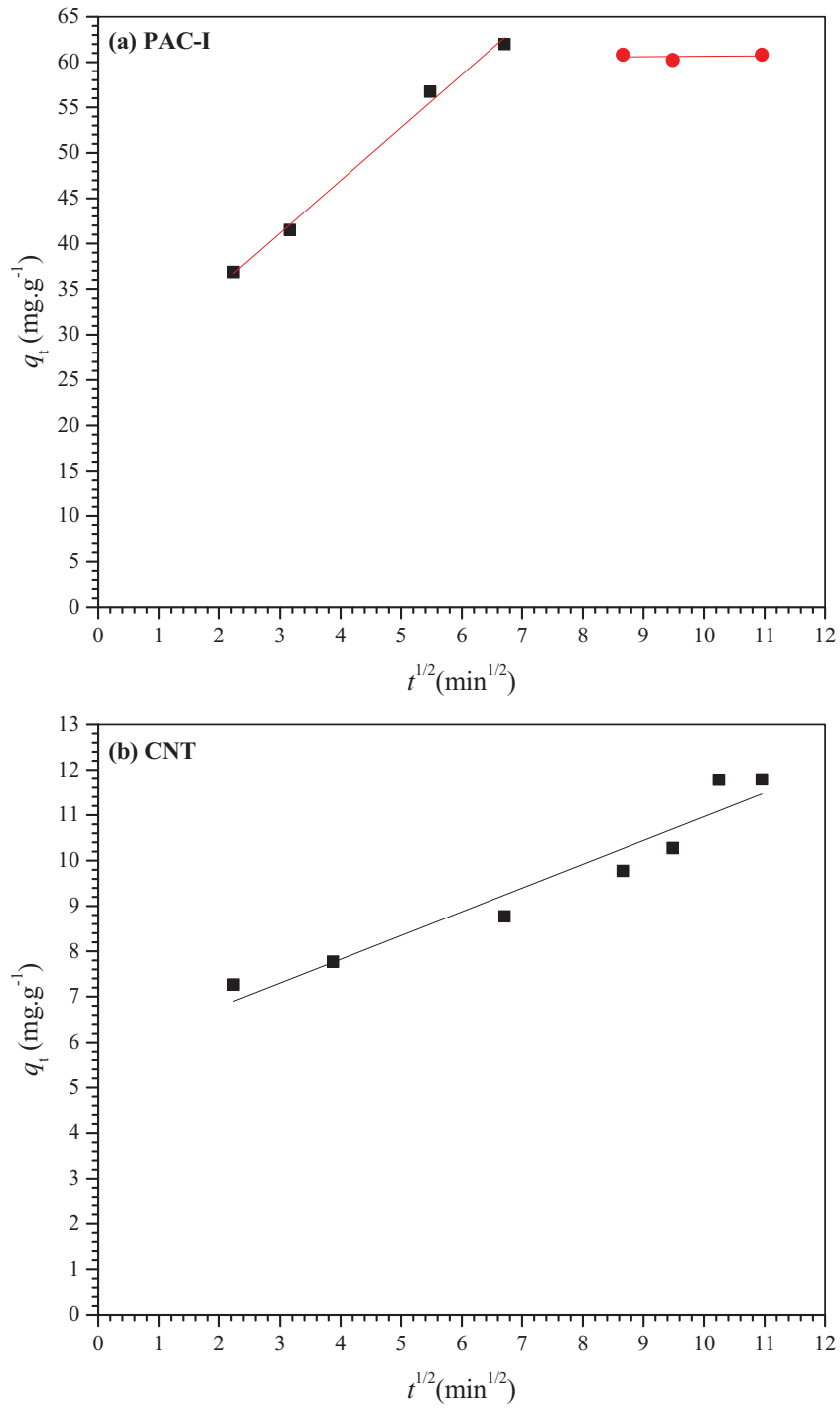

Fig. 4. Intraparticle diffusion model for SMX adsorption on (a) PAC-I and (b) CNT at $25^{\circ} \mathrm{C}$ and $\mathrm{pH} 7.0$.

SMX adsorption on PAC-I was relatively high, strengthening the hypothesis of a mixed mechanism is governing the adsorption process of SMX on PAC-I and CNT. Therefore, with basis on $\Delta \mathrm{H}^{\circ}$ and $\mathrm{E}_{\mathrm{a}}$ values is not possible to define a specific mechanism of adsorption of SMX on PAC-I and CNT. It suggests that both type of adsorption mechanisms may be contributing to the removal of SMX by PAC-I and CNT.

The extrathermodynamic parameters provide information on the adsorption transition state, so that the magnitude of the activation enthalpy $\left(\Delta H^{\ddagger}\right)$ and activation entropy $\left(\Delta S^{\ddagger}\right)$ would be good indicators of the transitional state (Gurgel et al., 2012). The $\Delta H^{\ddagger}$

Table 7

Activation energies and extrathermodynamic parameters calculated for the SMX adsorption on PAC-I and CNT at pH 7 and $2 \mathrm{~h}$ of contact.

\begin{tabular}{|c|c|c|c|c|c|c|c|}
\hline Adsorbent & Temperature $(K)$ & $\Delta G^{\ddagger}\left(\mathrm{kJ} \mathrm{mol}^{-1}\right)$ & $\Delta H^{\ddagger}\left(\mathrm{kJ} \cdot \mathrm{mol}^{-1}\right)$ & $\Delta S^{\ddagger}\left(\mathrm{J} \mathrm{K}^{-1} \mathrm{~mol}^{-1}\right)$ & $R^{2}$ & $E_{\mathrm{a}}\left(\mathrm{kJ} \mathrm{mol}^{-1}\right)$ & $R^{2}$ \\
\hline PAC- & 288.15 & -0.36 & 56.32 & 196.69 & 0.947 & 58.83 & 0.951 \\
\hline \multirow[t]{3}{*}{ I } & 298.15 & -2.32 & & & & & \\
\hline & 308.15 & -4.29 & & & & & \\
\hline & 318.15 & -6.26 & & & & & \\
\hline \multirow[t]{4}{*}{ CNT } & 288.15 & 4.35 & 82.19 & 270.12 & 0.892 & 84.70 & 0.897 \\
\hline & 298.15 & 1.65 & & & & & \\
\hline & 308.15 & -1.05 & & & & & \\
\hline & 318.15 & -3.75 & & & & & \\
\hline
\end{tabular}


values calculated for the SMX adsorption on PAC-I and CNT indicate that the transitional state would only be achieved by providing energy to the system (endothermic process), which agrees with the positive $E_{\mathrm{a}}$ values calculated for both adsorbents. In its turn, the $\Delta S^{\ddagger}$ values suggest that when the SMX molecules get closer to both adsorbents surface there is a displacement of water molecules (that were previously solvating the adsorbent and adsorbate) which leads to an increase in the system's degrees of freedom. Finally, the calculated $\Delta G^{\ddagger}$ values for both adsorbents indicate that the temperature increase contributes to reduce the energetic barrier for the formation of the transitional state. This is in agreement with the information given by the $E_{\mathrm{a}}$ and $\Delta H^{\ddagger}$ parameters.

\section{Conclusions}

In this study three commercial powdered activated carbons (PAC-I and II from pinus tree and coconut shells agricultural crop wastes), PAC-II from mineral carbon, and commercial carbon nanotubes (CNT) were tested for sulfamethoxazole (SMX) adsorption from water samples. Only PAC-I and CNT exhibited favorable SMX removal with maximum adsorption capacities at $25^{\circ} \mathrm{C}$ of $\sim 131 \mathrm{mg} \mathrm{g}^{-1}$ and $29 \mathrm{mg} \mathrm{g}^{-1}$ respectively. The Langmuir model best fitted the SMX adsorption on these adsorbents indicating there was a monolayer formation. The thermodynamic parameters indicate that SMX adsorption was exothermic $\left(\Delta H^{0}\right.$ of $-36.73 \mathrm{~kJ} \mathrm{~mol}^{-1}$ for PAC-I and $-38.96 \mathrm{~kJ} \mathrm{~mol}^{-1}$ for CNT) and spontaneous ( $\Delta G^{0}$ of $-38.80 \mathrm{~kJ} \mathrm{~mol}^{-1}$ for PAC-I and $-43.59 \mathrm{~kJ} \mathrm{~mol}^{-1}$ for CNT at $25^{\circ} \mathrm{C}$ ). Considering these thermodynamic parameters and the adsorbent characteristics it was possible to hypothesize that SMX adsorption on PAC-I was mainly due to electrostatic interaction, whereas for CNT was probably due to ion-dipole and $\pi-\pi$ interactions. The kinetic studies showed that the pseudo-second-order model best described the adsorption data, with $k_{2}$ values of 0.0035 and $0.0016 \mathrm{~g} \mathrm{mg}^{-1} \mathrm{~min}^{-1}$ for PAC-I and CNT, respectively. The calculated values of activation energies $\left(58.83 \mathrm{~kJ} \mathrm{~mol}^{-1}\right.$ for PAC-I and $84.70 \mathrm{~kJ} \mathrm{~mol}^{-1}$ for $\mathrm{CNT}$ ) corroborate with thermodynamic data. Therefore, the use of the low-cost and commercially available adsorbent PAC-I is greatly desirable to treat surface waters because the results can be directly applied to a pilot-scale plant, facilitating technology transfer.

\section{Acknowledgments}

The authors would like to thank the following agencies for their financial support: Universidade Federal de Ouro Ouro (UFOP), Financiadora de Estudos e Projetos (FINEP CARMEM project grant number 0973/10), Coordenação de Aperfeiçoamento de Pessoal de Nível Superior (CAPES), and Conselho Nacional de Desenvolvimento Científico (CNPq research productivity scholarship grant number 309569/2011-7). Authors would also like to thank Brittany Nicole Meighan (UFOP) for reviewing the manuscript for its English usage.

\section{Appendix A. Supplementary data}

Supplementary data associated with this article can be found, in the online version, at http://dx.doi.org/10.1016/j.indcrop.2015.05. 003

\section{References}

Çalıșkan, E., Göktürk, S., 2010. Adsorption characteristics of sulfamethoxazole and metronidazole on activated carbon. Sep. Sci. Technol. 45, 244-255.

Acero, J.L., Javier Benitez, F., Real, F.J., Teva, F., 2012. Coupling of adsorption coagulation, and ultrafiltration processes for the removal of emerging contaminants in a secondary effluent. Chem. Eng. J. 210, 1-8.
Alslaibi, T.M., Abustan, I., Ahmad, M.A., Abu Foul, A., 2013. A review: production of activated carbon from agricultural byproducts via conventional and microwave heating. J. Chem. Technol. Biotechnol. 88, 1183-1190.

Anirudhan, T.S., Radhakrishnan, P.G., 2008. Thermodynamics and kinetics of adsorption of $\mathrm{Cu}(\mathrm{II})$ from aqueous solutions onto a new cation exchanger derived from tamarind fruit shell. J. Chem. Thermodyn. 40, 702-709.

Awadallah-F, A., Mostafa, T., 2015. Effect of functionalized multi-walled carbon nanotubes with poly( $\mathrm{N}$-vinyl

pyrrolidone-co-2-acrylamido-2-methyl-1-propanesulfonic acid) on the release of tramadol hydrochloride. Chin. J. Polym. Sci. 33, 376-385.

Bhatnagar, A., Vilar, V.J.P., Botelho, C.M.S., Boaventura, R.A.R., 2010. Coconut-based biosorbents for water treatment - a review of the recent literature. Adv. Colloid Interface Sci. 160, 1-15.

Brown, C., 2000. The Global Outlook for Future Wood Supply from Forest Plantations. Rome.

Buckton, G., 2000. Interfacial Phenomena in Drug Delivery and Targeting. Taylor \& Francis, Switzerland.

Carabineiro, S.A.C., Thavorn-amornsri, T., Pereira, M.F.R., Serp, P., Figueiredo, J.L., 2012. Comparison between activated carbon, carbon xerogel and carbon nanotubes for the adsorption of the antibiotic ciprofloxacin. Catal. Today 186, 29-34.

Chen, H., Gao, B., Li, H., Ma, L.Q., 2011. Effects of pH and ionic strength on sulfamethoxazole and ciprofloxacin transport in saturated porous media. J. Contam. Hydrol. 126, 29-36.

Delgado, L.F., Charles, P., Glucina, K., Morlay, C., 2012. The removal of endocrine disrupting compounds, pharmaceutically activated compounds and cyanobacterial toxins during drinking water preparation using activated carbon - a review. Sci. Total Environ. 435-436, 509-525.

Do, D., 1998. Adsorption Analysis: Equilibria and Kinetics. Imperial College Press, London.

Duman, G., Onalt, Y., Okutucu, C., Onenc, S., Yanik, J., 2009. Production of activated carbon from pine cone and evaluation of its physical, chemical, and adsorption properties. Energy Fuel 23, 2197-2204.

Erbil, H.Y., 2006. Surface Chemistry of Solid and Liquid Interfaces. Blackwell Publishing Ltd., Malden, USA.

Fent, K., Weston, A.A., Caminada, D., 2006. Ecotoxicology of human pharmaceuticals. Aquat. Toxicol. 76, 122-159.

Ferreira, B.C.S., Teodoro, F.S., Mageste, A.B., Gil, L.F., de Freitas, R.P., Gurgel, L.V.A., 2015. Application of a new carboxylate-functionalized sugarcane bagasse for adsorptive removal of crystal violet from aqueous solution: kinetic, equilibrium and thermodynamic studies. Ind. Crop. Prod. 65C, 521-534.

Freundlich, H.M.F., 1906. Over the adsorption in solution. Z. Phys. Chem-Stoch Ve 57, 385-470.

Gurgel, L.V.A., Marabezi, K., Zanbom, M.D., Curvelo, A.A.D., 2012. Dilute acid hydrolysis of sugar cane bagasse at high temperatures: a kinetic study of cellulose saccharification and glucose decomposition. Part I: sulfuric acid as the catalyst. Ind. Eng. Chem. Res. 51, 1173-1185.

Gusmao, K.A.G., Gurgel, L.V.A., Melo, T.M.S., Gil, L.F., 2012. Application of succinylated sugarcane bagasse as adsorbent to remove methylene blue and gentian violet from aqueous solutions - kinetic and equilibrium studies. Dyes Pigm. 92, 967-974.

Ho, Y.S., McKay, G., 1998. Kinetic models for the sorption of dye from aqueous solution by wood. Process Saf. Environ. Prot. 76, 183-191.

Ho, Y.-S., 2006. Review of second-order models for adsorption systems. J. Hazard. Mater. 136, 681-689.

Ji, L., Chen, W., Zheng, S., Xu, Z., Zhu, D., 2009. Adsorption of sulfonamide antibiotics to multiwalled carbon nanotubes. Langmuir 25, 11608-11613.

Lagergren, S.Y., 1898. Zur theorie der sogenannten adsorption gelöster stoffe, Kungliga Svenska Vetenskapsakademiens. Handlingar 24, 1-39.

Langmuir, I., 1918. The adsorption of gases on plane surfaces of glass, mica and platinum. J. Am. Chem. Soc. 40, 1361-1403.

Larkin, P., 2011. Infrared and Raman Spectroscopy; Principles and Spectral Interpretation. Elsevier Science.

Li, W., Peng, J.H., Zhang, L., Yang, K.B., Xia, H.Y., Zhang, S.M., Guo, S.H., 2009. Preparation of activated carbon from coconut shell chars in pilot-scale microwave heating equipment at 60kW. Waste Manage. 29, 756-760.

Lima, D.S., Baêta, B.L., Aquino, S., Libânio, M., Afonso, R.C.F., 2014. Removal of pharmaceuticals and endocrine disruptor compounds from natural waters by clarification associated with powdered activated carbon. Water Air Soil Pollut. 225, 1-12.

Liu, Y., 2009. Is the free energy change of adsorption correctly calculated? J. Chem Eng. Data 54, 1981-1985.

Masters, P.A., O’Bryan, T.A., Zurlo, J., Miller, D.Q., Joshi, N., 2003. Trimethoprim-sulfamethoxazole revisited. Ach. Intern. Med. 163, 402-410

Melo, S.A.S., Trovó, A.G., Bautitz, I.R., Nogueira, R.F.P., 2009. Degradação de fármacos residuais por processos oxidativos avançados. Quim. Nova 32, 188-197.

Mezohegyi, G., van der Zee, F.P., Font, J., Fortuny, A., Fabregat, A., 2012. Towards advanced aqueous dye removal processes: a short review on the versatile role of activated carbon. J. Environ. Manage. 102, 148-164.

Momčilović, M., Purenović, M., Bojić, A., Zarubica, A, Ranđelović, M. 2011. Removal of lead(II) ions from aqueous solutions by adsorption onto pine cone activated carbon. Desalination 276, 53-59.

Noh, J.S., Schwarz, J.A., 1990. Effect of $\mathrm{HNO}_{3}$ treatment on the surface-acidity of activated carbons. Carbon 28, 675-682. 
Nunes, D.L., Franca, A.S., Oliveira, L.S., 2011. Use of Raphanus sativus L. press cake a solid residue from biodiesel processing, in the production of adsorbents by microwave activation. Environ. Technol. 32, 1073-1083.

Ogata, F., Tominaga, H., Kangawa, M., Inoue, K., Kawasaki, N., 2012. Removal of sulfa drugs by sewage treatment in aqueous solution systems: activated carbon treatment and ozone oxidation. J. Oleo Sci. 61, 217-225.

Onesios, K., Yu, J., Bouwer, E., 2009. Biodegradation and removal of pharmaceuticals and personal care products in treatment systems: a review. Biodegradation 20, 441-466.

Rao, G.P., Lu, C., Su, F., 2007. Sorption of divalent metal ions from aqueous solution by carbon nanotubes: a review. Sep. Purif. Technol. 58, 224-231.

Richard, J., Boergers, A., vom Eyser, C., Bester, K., Tuerk, J., 2014. Toxicity of the micropollutants bisphenol A, ciprofloxacin, metoprolol and sulfamethoxazole in water samples before and after the oxidative treatment. Int. J. Hyg. Environ. Health 217, 506-514.

Rodrigues, K.L.T., Sanson, A.L., Quaresma Gomes, A.d.V., da Silva, R.d.P., GA, Afonso, R.J.d.C.F., 2014. Chemometric approach to optimize the operational parameters of ESI for the determination of contaminants of emerging concern in aqueous matrices by LC-IT-TOF-HRMS. Microchem. J. 117, 242-249.

Santos, L.H.M.L.M., Araújo, A.N., Fachini, A., Pena, A., Delerue-Matos, C., Montenegro, M.C.B.S.M., 2010. Ecotoxicological aspects related to the presence of pharmaceuticals in the aquatic environment. J. Hazard. Mater. 175, 45-95
Sips, R., 1948. On the structure of a catalyst surface. J. Chem. Phys. 16, 490-495. Temkin, M., Pyzhev, V., 1940. Kinetics of ammonia synthesis on promoted iron catalysts. Acta physiochim. URSS 12, 217-222.

Terrones, M., 2004. Carbon nanotubes: synthesis and properties: electronic devices and other emerging applications. Int. Mater. Rev. 49, 325-377.

Van Boeckel, T.P., Gandra, S., Ashok, A., Caudron, Q., Grenfell, B.T., Levin, S.A., Laxminarayan, R, 2014. Global antibiotic consumption 2000 to 2010: an analysis of national pharmaceutical sales data. Lancet Infect. Dis. 14, 742-750.Weber, W.J., Morris, J.C., 1963. Kinetics of adsorption on carbon from solution. J. San. Eng. Div. 89, 31-60.

Worch, E., 2012. Adsorption Technology in Water Treatment: Fundamentals, Processes, and Modeling. De Gruyter, Berlin.

Yargeau, V., Huot, J.C., Rodayan, A., Rouleau, L., Roy, R., Leask, R.L., 2008. Impact of degradation products of sulfamethoxazole on mammalian cultured cells. Environ. Toxicol. 23, 492-498.

de la Cruz, E., Fournier, M.L., Garcia, F., Molina, A., Chavarria, G., Alfaro, M., Ramirez, F., Rodriguez, C., 2014. Hazard prioritization and risk characterization of antibiotics in an irrigated Costa Rican region used for intensive crop, livestock and aquaculture farming. J. Environ. Biol. 35, 85-98. 